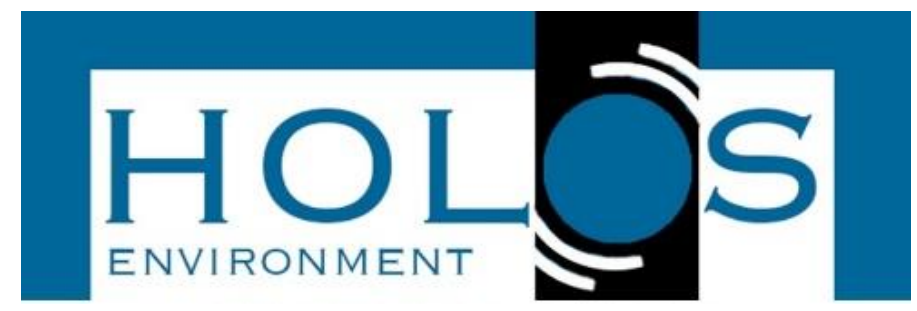

\title{
COMPRESSIBILIDADE EM MISTURAS DE SOLO LATERÍTICO, BENTONITA E FIBRAS PARA USO EM BARREIRAS DE FLUXO
}

\section{COMPRESSIBILITY OF LATERITIC SOIL, BENTONITE AND FIBRE MIXTURES FOR LINERS PROPOSALS}

\author{
Thiago Luiz Coelho Morandini ${ }^{1}$ Vinícius Carvalho Schneider ${ }^{2}$
}

Artigo recebido em: 04/10/2016 e aceito para publicação em: 05/07/2017.

DOI: http://dx.doi.org/10.14295/holos.v17i1.11887

Resumo: Os solos lateríticos devido à sua elevada resistência mecânica quando compactados, os solos lateríticos possuem potencial aplicabilidade em obras geotécnicas, inclusive em barreiras de fluxos, tais como liners em aterros sanitários, cut-off de barragens, e cut-off walls para contenção de plumas contaminantes. Neste caso, também são requeridos baixa condutividade hidráulica e compatibilidade com os fluidos circundantes, sendo a adição de bentonita a alternativa usualmente empregada para a diminuição da condutividade hidráulica e aumento da capacidade sorciva. Por outro lado, a bentonita pode aumentar a compressibilidade dos solos, deformando-o e comprometendo a integridade da barreira de fluxo. Este artigo apresenta os resultados de compressibilidade em misturas de um solo laterítico, bentonita e fibras. Foram testadas amostras de solo laterítico, mistura contendo solo laterítico e $5 \%$ de bentonita e mistura contendo solo laterítico, $5 \%$ de bentonita e $1 \%$ de fibras de polipropileno. Os ensaios englobaram caracterização mineralógica do solo laterítico e da bentonita, avaliação das propriedades geotécnicas e avaliação de compressibilidade em célula de adensamento com 5 estágios de carregamento. De forma geral, os resultados demonstraram aumento da plasticidade e da compressibilidade no solo laterítico devido à adição de bentonita. Por outro lado, a adição de fibras de polipropileno à mistura solo-bentonita não resultou em diminuição da compressibilidade, demonstrando ineficiência da aplicação de fibras de polipropileno para o uso em barreiras de fluxo.

Palavras-chave: Barreiras de fluxo. Solo laterítico. Bentonita. Fibras. Compressibilidade.

Abstract: Lateritic soils have potential applicability in geotechnical works because of its high mechanical strength when compacted, including flow barriers, such as liners in landfills, dam's cut-off walls, and cutoff walls for containing contaminants. In this case, they are also required low hydraulic conductivity and compatibility with the surrounding fluid with the addition of bentonite the alternative usually employed to reduce the hydraulic conductivity and increased sorption capacity. On the order hand, the bentonite can increase the compressibility of the soil, deforming it and jeopardizing the integrity of the flow barrier. This paper presents the results of compressibility in mixtures of a lateritic soil, bentonite and fibers. Were tested lateritic soil and mixtures containing lateritic soil and $5 \%$ of bentonite besides mixture containing lateritic soil, $5 \%$ of bentonite and $1 \%$ of polypropylene fibers. The tests encompassed mineralogical characterization of lateritic soil and bentonite, evaluation of geotechnical properties and evaluation of compressibility in consolidation cell with 5 loading stages. Overall, results demonstrated increased of plasticity and compressibility in the laterite because of the addition of bentonite. On the order hand, the addition of polypropylene fibers in soil-bentonite mixture did not result in decreased of compressibility, demonstrating inefficient application of polypropylene fibers for use in liners.

Keywords: Liners. Lateritic Soil. Bentonite. Fibers. Compressibility.

\footnotetext{
${ }^{1}$ Centro Federal de Educação Tecnológica de Minas Gerais. Email: (thiagomorandini@yahoo.com.br)

${ }^{2}$ Centro Federal de Educação Tecnológica de Minas Gerais. Email: (vica.schneider@gmail.com)
} 


\section{INTRODUÇÃO}

Os solos tropicais empregados em barreiras de fluxo muitas vezes não atendem aos valores mínimos de condutividade hidráulica exigidos em obras de contenção de resíduo (normalmente o máximo aceitável deve ser $10^{-7} \mathrm{~cm} / \mathrm{s}$, segundo CETESB, 1993). As normas internacionais mais rígidas, tais como a alemã e a austríaca, exigem uma condutividade hidráulica inferior a $5 \times 10^{-8} \mathrm{~cm} / \mathrm{s}$ (Koch, 2002). Por esta razão, a adição da bentonita a torna-se uma opção para se reduzir a condutividade hidráulica.

Além da redução da condutividade hidráulica, a bentonita ainda possui propriedades coloidais desejáveis em materiais impermeabilizantes, tais como expansividade, elevada capacidade de troca catiônica e elevada capacidade sorciva e atenuante. Estas propriedades aumentam a capacidade de impermeabilizar e/ou retardar o fluxo de água ou contaminantes.

Destacam-se estudos que avaliam a diminuição da condutividade hidráulica em misturas de bentonita a outros solos (Chapuis, 1990; Sivapullaiah et al., 1998; Stewart et al., 2003), assim como trabalhos que avaliam especificamente a alteração de propriedades de solos lateríticos e suas misturas com bentonita para aplicações de sistemas horizontais de selagem (Anderson e Hee, 1995; Osinubi e Nwaiwu, 2002; Farnezi e Leite, 2007).

Em detrimento à diminuição da condutividade hidráulica, é esperado que a mistura com bentonita aumente a compressibilidade dos solos, podendo gerar deformações excessivas e comprometimento da integridade da barreira. Por este motivo, as barreiras de solo compactado geralmente são empregadas em associação com geossintéticos.

Da mesma forma, alguns estudos abordam a adição de fibras em solos visando a melhoria nas propriedades mecânicas dos solos, tais como Heineck (2002), Michalowski e Cermák (2003), Donato et al. (2004), Consoli et. al (2007, 2009), Diambra et al. (2010). Estes estudos tem como propósito a introdução de um material de elevada resistência a tração para aumentar a resistência ao cisalhamento e diminuir a compressibilidade dos solos.

Existem diversos tipos de fibras empregadas no reforço de solos, podendo ser classificadas em quatro classes: naturais, minerais, metálicas e poliméricas. Cada um desses tipos possui propriedades (elasticidade, aderência, durabilidade, resistência a 
tração, flexibilidade) indicadas para determinada finalidade. Dentre as principais fibras empregadas em solos, Hannant (1994) cita as fibras vegetais de bambu, capim, malva, coco, sisal, linho e cana-de-açúcar, enquanto Taylor (1994) faz referência às fibras minerais de carbono, vidro e amianto. De relevânica no presente estudo, Taylor (1994) cita as fibras de polipropileno como possuindo elevada flexibilidade e módulo de elasticidade em torno de $8 \mathrm{GPa}$.

Em conexão com os referidos trabalhos, o presente artigo apresenta os resultados de uma pesquisa que teve por objetivo principal avaliar a influência do uso de fibras de polipropileno na compressibilidade de misturas de solo laterítico e bentonita. Estes resultados complementam os estudos apresentados em Morandini e Leite (2015), onde foi demonstrada a diminuição considerável da condutividade hidráulica dos solos tropicais estudados pela adição de bentonita.

Por consequência, a presente pesquisa tem por motivação o preenchimento de lacunas existentes em estudos de misturas bentoníticas em relação às suas propriedades mecânicas, sobretudo em relação à compressibilidade de solos compactados. Especificamente, o estudo apresentado possibilita a aplicação de seus resultados em obras de liners em aterros sanitários, cut-off de barragens, e cut-off walls para contenção de plumas contaminantes.

\section{MATERIAL E MÉTODOS}

Para os testes de compressibilidade foi coletada amostra de solo de um perfil tipicamente laterítico nas proximidades da BR-356 no município de Nova Lima. A bentonita empregada nas misturas é a bentonita sódica Brasgel $\Theta$, da fabricante Bentonit União Nordeste S/A. A fibra utilizada foi a de polipropileno FibroMac® da empresa Diprotec. As características básicas da fibra foram fornecidas pela fabricante, sendo comprimento de $12 \mathrm{~mm}$, diâmetro de $18 \mu \mathrm{m}$ e resistência nominal à tração de $240 \mathrm{MPa}$.

As proporções de solo e bentonita foram definidas seguindo indicações de valores de Morandini e Leite (2015). Deste modo, têm-se as seguintes denominações:

- Amostra SL: $100 \%$ de solo laterítico;

- Amostra SLB: $95 \%$ de solo laterítico e $5 \%$ de bentonita;

- Amostra SLBF: $94 \%$ de solo laterítico, $5 \%$ de bentonita e $1 \%$ de fibras de polipropileno. 
Os procedimentos adotados na preparação das amostras foram 0 destorroamento, homogeneização, peneiramento e estocagem em recipientes adequados, conforme a NBR 6457 (1986). Após esses procedimentos de preparação, foram realizados os ensaios de caracterização, avaliação de propriedades geotécnicas e avaliação de compressibilidade, cujos métodos são descritos a seguir.

\subsection{Caracterização do Solo Laterítico, Bentonita e Misturas}

A caracterização do solo laterítico e da bentonita foi realizada mediante ensaios de difratometria de raios- $X$, realizada em lâminas vítreas normais em análise de pó total. Para confecção destas lâminas as amostras foram pulverizadas, homogeneizadas e peneiradas (malha de 200 mesh - 0,074 mm). O procedimento do ensaio de difração de raios- $X$ foi realizado conforme a rotina típica de laboratórios de microscopia óptica utilizando velocidade de varredura de $1,2^{\circ}$ por segundo e varredura de $1^{\circ}$ a $35^{\circ}$.

As propriedades geotécnicas do solo laterítico, bentonita e misturas foram determinadas por meio de ensaios de limites de Atterberg, granulometria conjunta e a massa específica dos sólidos.

Os ensaios de limite de liquidez e limite de plasticidade foram executados conforme procedimentos dispostos nas normas NBR 6459 (1984) e NBR 7180 (1984), respectivamente. $O$ ensaio de granulometria foi realizado segundo os procedimentos descritos na NBR 7181 (1984), com a escala granulométrica apresentada na NBR 6502 (1993). Na fase de sedimentação da granulometria conjunta foi empregada solução de hexametafosfato de sódio com a concentração de 45,7 g/L.

Para a obtenção da massa específica dos sólidos, foi realizado o ensaio conforme métodos descritos na NBR 6508 (1984). Ressalta-se que, devido à grande expansividade da bentonita, optou-se pela utilização $20 \mathrm{~g}$ deste material em detrimento dos $50 \mathrm{~g}$ indicados na referida norma.

\subsection{Compressibilidade}

O ensaio de adensamento foi realizado em prensa tipo Bishop conforme procedimentos descritos na NBR 12007 (1990). Optou-se por trabalhar com amostras deformadas compactadas na umidade ótima e massa específica seca máxima 
predeterminadas em ensaio de compactação Proctor normal. Após a moldagem, as amostras foram submetidas à carga hidráulica para saturação.

O procedimento operacional foi de cinco estágios de carregamentos de 25, 50 , 100, 200 e 400 kPa. Para cada estágio de carregamento procedeu-se a leitura do extensômetro nos tempos de $15 \mathrm{~s}, 30 \mathrm{~s}, 1$ minuto, 2 minutos, 4 minutos, 8 minutos, 15 minutos, 30 minutos, 1 hora, 2 horas, 4 horas, 8 horas e 24 horas.

Os cálculos foram efetuados conforme indicado na NBR 12007 (1990), medindo-se o índice de vazios e grau de saturação iniciais, assim como as leituras de deformação no tempo e o índice de vazios no final de cada estágio de carregamento. A seguir foi delineada a curva de índice de vazios em função da tensão vertical e calculados o coeficiente de variação volumétrica (equação 1), o coeficiente de compressibilidade (equação 2) e o índice de compressão (equação 3) para cada amostra.

$$
\begin{gathered}
m_{v}=\frac{\Delta \varepsilon}{\Delta \sigma_{v}} \\
a_{v}=\frac{\Delta e}{\Delta \sigma_{v}} \\
C_{c}=\frac{\Delta e}{\Delta \log \sigma_{v}}
\end{gathered}
$$

Onde $\Delta \varepsilon$ é a variação de deformação, $\Delta \sigma_{v}$ é a variação de tensão vertical e $\Delta e$ é a variação de índice de vazios. A variação de $\Delta \log \sigma_{v}$ é medido no segmento de compressão virgem da curva de adensamento.

Além dos parâmetros de compressibilidade também foi calculada a variação relativa $(\Delta)$ destes parâmetros de acordo com a equação 4 .

$$
\Delta=\frac{X-X_{R}}{X_{R}}
$$

Onde $X_{R}$ é a grandeza de referência e $X$ é a grandeza da qual está sendo medida a variação relativa. 


\section{RESULTADOS E DISCUSSÕES}

\subsection{Caracterização do Solo Laterítico, Bentonita e misturas}

As Figuras 1 e 2 registram respectivamente os resultados de difração de raios$X$ das amostras de solo laterítico e bentonita. Como esperado, na bentonita foi encontrada principalmente a montmorilonita como mineral predominante, além de traços de caulinita, attapulgita e mica. Enquanto que na amostra de solo laterítico, os minerais encontrados são compatíveis com solos tropicais muito evoluídos pedologicamente, tais como caulinita, hematita, gibsita e goethita.

Figura 1 - Difração de raios-X da amostra de solo laterítico

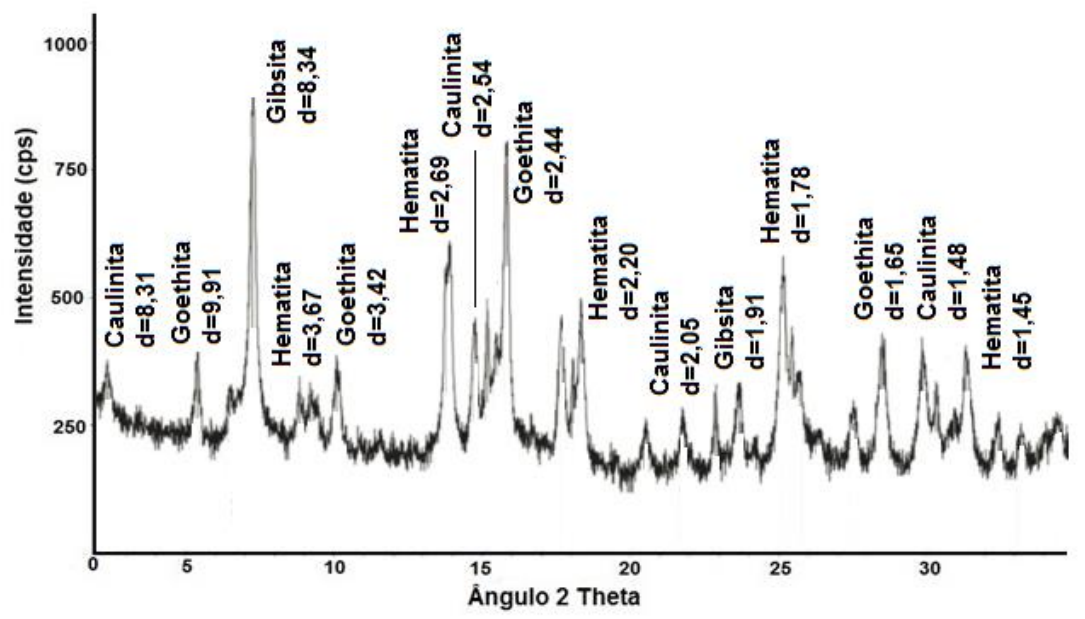

Figura 2 - Difração de raios-X da amostra de bentonita

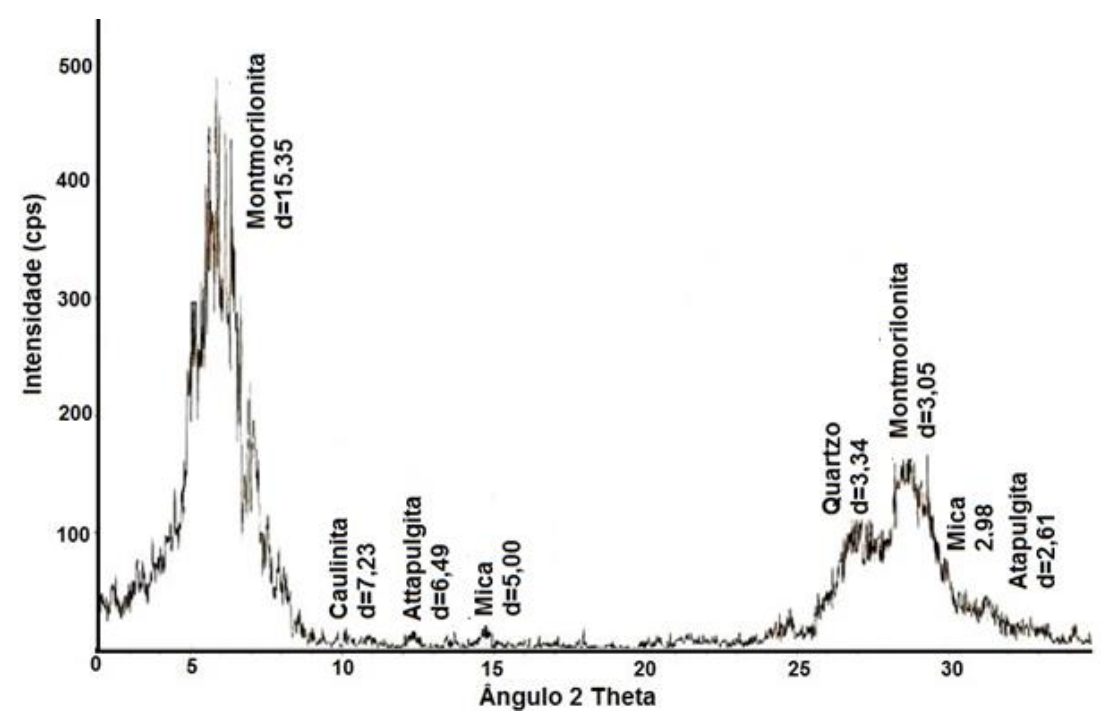


A Tabela 1 apresenta as propriedades geotécnicas do solo laterítico e das misturas. Verifica-se que o solo laterítico possui limite de liquidez $\left(\omega_{L}\right)$ e índice de plasticidade (IP) relativamente baixos, resultante de uma granulometria composta por apenas $14 \%$ de fração argila. Observa-se que a adição de bentonita promoveu aumento de $\omega L$ e IP na amostra SLB. O $\omega L$ passou de $36 \%$ para $63 \%$, enquanto o IP passou de $8 \%$ para $27 \%$. Este aumento já era esperado devido à elevada plasticidade de bentonita. Enquanto que no limite de plasticidade $(\omega L)$, observou-se apenas um ligeiro aumento devido à adição de bentonita.

Por outro lado, como indicam os resultados de limites de Atterberg da amostra SLBF (Tabela 1), as fibras de polipropileno pouco impactaram na plasticidade em relação à amostra SLB. Devido ao tamanho relativamente grande da fibra (18 $\mu \mathrm{m}$ de espessura) comparado com o diâmetro equivalente da argila (máximo de $5 \mu \mathrm{m}$ ), era esperada diminuição mais significativa da plasticidade entre as amostras SLBF e SLB.

Tabela 1 - Propriedades geotécnicas do solo laterítico e das misturas

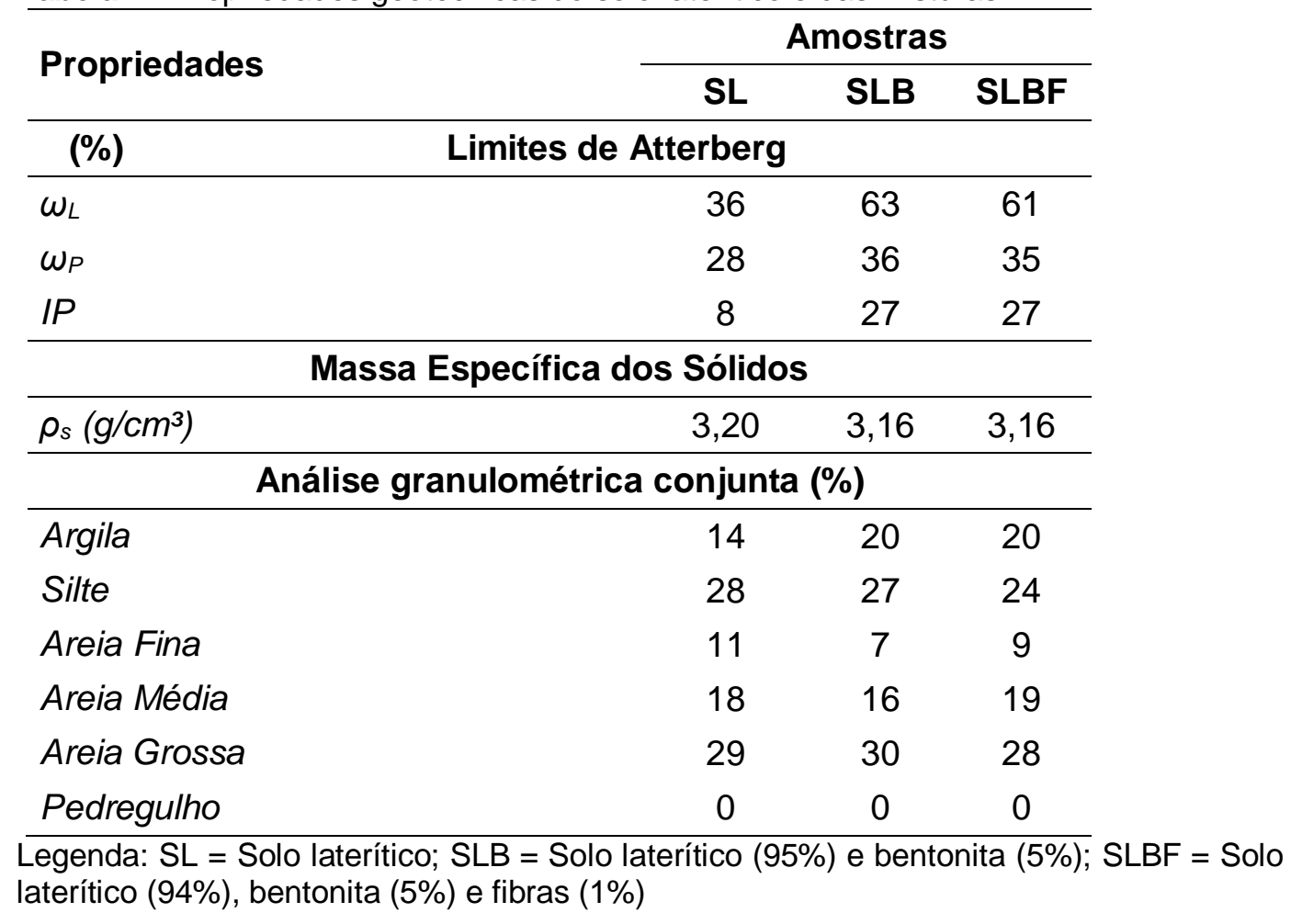

Ainda na Tabela 1, observa-se que a massa específica dos grãos do solo laterítico puro é um pouco maior do que o obtido nas misturas. Este fato deve-se à menor densidade dos minerais presentes na bentonita em relação aos minerais presentes no solo laterítico. 
Em termos de granulometria, registra-se que o solo laterítico se trata de uma areia silto-argilosa. A bentonita adicionada refletiu, como esperado, em aumento da fração argila de $14 \%$ para $20 \%$. O aumento da fração argilosa pode representar alterações significativas em propriedades mecânicas e hidráulicas do solo laterítico, tais como aumento da plasticidade, diminuição da condutividade hidráulica, aumento da capacidade troca catiônica e aumento da compressibilidade.

Por outro lado, a adição de fibra pouco alterou a fração argilosa da amostra SLB. Este fato, provavelmente, deve-se a pequena quantidade empregada na mistura (1\%). Mesmo assim, era esperado que a adição de fibras (material de elevada rigidez e elevada resistência à tração) diminuísse a compressibilidade da amostra SLB.

\subsection{Compressibilidade}

A Figura 3 insere as curvas de adensamento para as amostras de solo laterítico (SL), sua mistura com bentonita (SLB) e sua mistura com bentonita e fibras (SLBF). Constata-se primeiramente que o índice de vazios inicial é de aproximadamente 0,90 para o solo laterítico, valor considerado relativamente alto para solos arenosos lateríticos. Esse índice de vazios inicial aumentou para a amostra SLB, como esperado. Entretanto, ao contrário do esperado, o índice de vazios inicial obtido para a amostra SBF foi superior ao obtido para a amostra SLB.

Figura 3 - Índice de vazios em função da tensão vertical

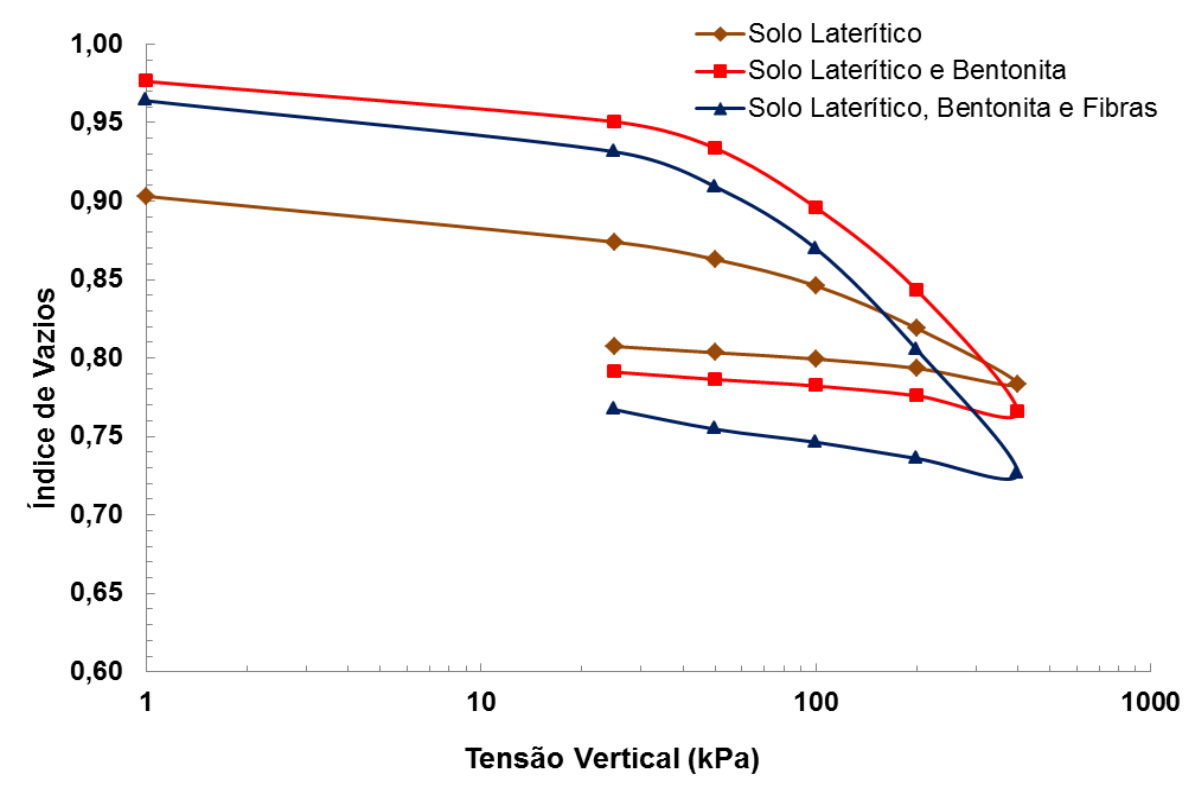


Ao avaliar a reta de compressão da amostra virgem na Figura 3, é possível observar uma maior inclinação para a amostra SLB em relação à amostra SL, assim como uma maior inclinação para a amostra SLBF em relação à amostra SLB, revelando aumento de compressibilidade pela adição da bentonita (como esperado) e aumento ainda maior da compressibilidade com a adição das fibras. Esta tendência também pode ser verificada com o índice de vazios mínimos obtidos pelas amostras sob a tensão vertical de $400 \mathrm{kPa}$, cuja ordem foi SLBF $<$ SLB $<$ SL.

Para melhor visualização do efeito da bentonita e das fibras sobre a variação do índice de vazios, mostra-se na Figura 4 a variação relativa do índice de vazios em função da tensão vertical. Observa-se que no solo laterítico puro houve uma variação do índice de vazios de aproximadamente $13 \%$ em relação ao índice de vazios inicial. Enquanto que para as amostras SLB e SLBF, este valor foi de aproximadamente $21 \%$ e $24 \%$, respectivamente. Ficou demonstrado dessa forma que o efeito da bentonita aumentou a compressibilidade do solo laterítico e a fibra não diminuiu esta característica.

Figura 4 - Variação relativa do índice de vazios em função da tensão vertical

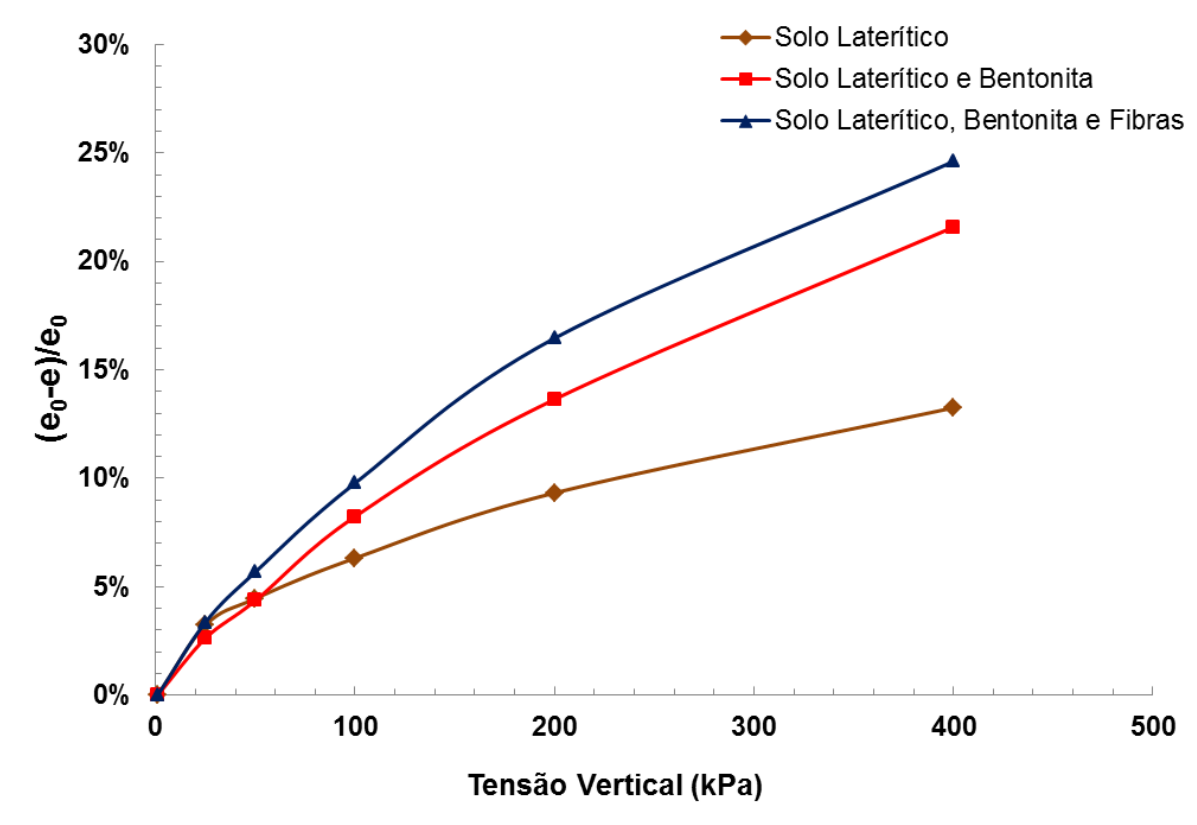

A Tabela 2 apresenta os resultados de coeficiente de variação volumétrica $\left(m_{v}\right)$, o coeficiente de compressibilidade $\left(a_{v}\right)$ e o índice de compressão $\left(C_{c}\right)$, enquanto a Tabela 3 apresenta a variação relativa destes parâmetros, comparando-os entre as amostras SL, SLB e SLBF. 
Tabela 2 - Parâmetros de compressibilidade do solo laterítico e das misturas

\begin{tabular}{cccc}
\hline \multirow{2}{*}{ Parâmetros } & \multicolumn{3}{c}{ Amostras } \\
\cline { 2 - 4 } & SL & SLB & SLBF \\
\hline$m_{v}\left(\mathrm{~m}^{2} / \mathrm{kN}\right)$ & $1,6 \times 10^{-04}$ & $2,7 \times 10^{-04}$ & $3,0 \times 10^{-04}$ \\
$a_{v}\left(\mathrm{~m}^{2} / \mathrm{kN}\right)$ & $3,0 \times 10^{-04}$ & $5,8 \times 10^{-04}$ & $5,9 \times 10^{-04}$ \\
$C_{c}$ & 0,10 & 0,22 & 0,25
\end{tabular}

Legenda: $\overline{\mathrm{SL}}=$ Solo laterítico; $\mathrm{SLB}=$ Solo laterítico $(95 \%)$ e bentonita $(5 \%) ; \mathrm{SLBF}=$ Solo laterítico $(94 \%)$, bentonita $(5 \%)$ e fibras (1\%)

Tabela 3 - Variação relativa dos parâmetros de compressibilidade

\begin{tabular}{cccc}
\hline \multirow{2}{*}{ Parâmetros } & \multicolumn{3}{c}{ Variação Relativa } \\
\cline { 2 - 4 } & $\Delta$ SLB/SL & $\Delta$ SLBF/SL & $\Delta$ SLBF/SLB \\
\hline$m_{v}\left(\mathrm{~m}^{2} / \mathrm{kN}\right)$ & $70 \%$ & $92 \%$ & $13 \%$ \\
$a_{v}\left(\mathrm{~m}^{2} / \mathrm{kN}\right)$ & $76 \%$ & $98 \%$ & $13 \%$ \\
$C_{c}$ & $114 \%$ & $137 \%$ & $10 \%$
\end{tabular}

Legenda: $\mathrm{SL}=$ Solo laterítico; SLB = Solo laterítico (95\%) e bentonita (5\%); SLBF = Solo laterítico $(94 \%)$, bentonita $(5 \%)$ e fibras $(1 \%)$

A Tabela 2, registra que os parâmetros de compressibilidade do solo laterítico são compatíveis aos encontrados em solos tropicais pouco compressíveis, apesar do elevado índice de vazios inicial observado. De fato, o valor de $C c$ encontrado no solo laterítico está compatível com os ajustes propostos por Terzaghi e Peck (1967) e Sridharan e Nagaraj (2000) para análises de Cc em função das propriedades geotécnicas dos solos. Além disso, observa-se que houve aumento de $m_{v}$, $a_{v}$ e $C_{c}$ da amostra SLB em relação à amostra SL e da amostra SLBF em relação à amostra SLB, confirmando o aumento da compressibilidade pela adição da bentonita assim como pela adição das fibras.

Enquanto que a Tabela 3, demonstra elevada variação relativa dos parâmetros de compressibilidade entre as amostras SLB e SL, assim como entre as amostras SLBF e SL. Por sua vez a variação relativa dos parâmetros de compressibilidade entre as amostras SLBF e SLB mostrou-se menor, porém positiva. Observa-se que (mv) e (av) aumentaram de 13\%, enquanto o (Cc) aumentou 10\% entre as amostras SLBF e SLB, significando que as fibras não evitaram o aumento da compressibilidade pela adição da bentonita, e sim potencializaram ainda mais este efeito negativo. 


\section{CONCLUSÕES}

O estudo da adição de bentonita e fibras ao solo laterítico constatou relevantes alterações nas propriedades geotécnicas e na compressibilidade deste solo para aplicação em barreiras de fluxo, tais como:

- O solo laterítico estudado possui baixa plasticidade para ser aplicado puro em obras de barreiras de fluxo. A adição de bentonita aumentou consideravelmente esta plasticidade, enquanto a adição de fibras não demonstrou alteração significativa na plasticidade da mistura solo laterítico e bentonita;

- A granulometria do solo laterítico é de uma areia silto-argilosa, não indicada para o uso em obras de impermeabilização. A adição de bentonita melhora este aspecto e a adição de fibras não demonstrou interferência na granulometria da mistura solo laterítico e bentonita;

- O índice de vazios inicial do solo laterítico é relativamente alto, fato que pode representar uma elevada condutividade hidráulica para a aplicação deste solo puro em barreiras de fluxo;

- A adição de bentonita aumentou consideravelmente os parâmetros de compressibilidade do solo laterítico, fato que pode comprometer a integridade física de uma barreira composta por solo-bentonita. $O$ índice de compressibilidade aumentou 114\%;

- A adição de fibras à mistura solo laterítico e bentonita não obteve a diminuição de compressibilidade esperada. Ao contrário, foi observado um aumento dos parâmetros de compressibilidade, sendo que, no índice de compressibilidade, foi observado aumento de $10 \%$ entre as amostras SLBF e SLB.

Dessa forma, recomenda-se que estudos mais detalhados devem ser realizados para o emprego de misturas solo laterítico bentonita para o uso em barreiras de fluxo, sobretudo ensaios de adensamento. Por outro lado, o uso de fibras, a princípio, não deve ser aplicado com a finalidade de reduzir a compressibilidade. Entretanto, a adição de fibras de polipropileno a outros solos ou o uso de outros tipos de fibras podem resultar na diminuição de compressibilidade. 


\section{AGRADECIMENTOS}

Os autores agradecem ao CEFET-MG e à Fundação de Amparo a Pesquisa de Minas Gerais (CAPES), que concedeu uma subvenção para o segundo autor. Agradecimento especial é dado à Bentonit União Nordeste SA, representada por Pedro Paulo Furtado Gouveia, que gentilmente doou amostras de bentonita utilizadas nesta pesquisa.

\section{REFERÊNCIAS}

ABNT - Associação Brasileira de Normas Técnicas. NBR 6457: amostras de solo preparação para ensaios de compactação e ensaios de caracterização. Rio de Janeiro: ABNT, 1986.

ABNT - Associação Brasileira de Normas Técnicas. NBR 6459: determinação do limite de liquidez. Rio de Janeiro: ABNT, 1984.

ABNT - Associação Brasileira de Normas Técnicas. NBR 6502: solos e rochas terminologia. Rio de Janeiro: ABNT, 1993.

ABNT - Associação Brasileira de Normas Técnicas. NBR 6508: grãos de solos que passam na peneira de 4,8 mm - determinação da massa específica. Rio de Janeiro: ABNT, 194.

ABNT - Associação Brasileira de Normas Técnicas. NBR7180: determinação do limite de plasticidade. Rio de Janeiro: ABNT, 1984.

ABNT - Associação Brasileira de Normas Técnicas. NBR 7181: análise granulométria. Rio de Janeiro: ABNT, 1984.

ABNT - Associação Brasileira de Normas Técnicas. NBR 12007: solo - ensaio de adensamento unidimensional. Rio de Janeiro: ABNT, 1990.

Anderson, S. A. e Hee, B. H. (1995). Hydraulic conductivity of compacted lateritic soil with bentonite admixture. Environmental e Engineering Geoscience, v. 1, n. 3, p. 299-312.

CETESB - Companhia de Tecnologia de Saneamento Ambiental. Resíduos sólidos Industriais. São Paulo, 1993.

CHAPUIS, R. P. Sand-bentonite liners: predicting permeability from laboratory tests.

Canadian Geotechnical Journal, v. 27, p. 47-57, 1990.

CONSOLI, N. C.; CASAGRANDE, M. D. T.; COOP, M.R. Performance of a fibre reinforced sand at large shear strains. Geotecnique, n. 57, p. 1-6, 2007.

CONSOLI, N. C.; CASAGRANDE, M. D. T.; TOMHÉ, A; DALLA ROSA; FAHEY. P Effect of relative density on plate loading tests on fibre-reinforced sand. Geotecnique, n. 59, v. 5, p. 471-476, 2009. 
DIAMBRA A.; IBRAIM E; MUIR WOOD D; RUSSELL A. R.Fibre reinforced sands:

Experiments and modelling. Geotextiles and Geomembranes, n. 28, p. 238-250, 2010.

DONATO, M.; FOPPA, D.; CERATTI, J. A. P.; CONSOLI, N. C. Fibras de polipropileno como reforço para materiais geotécnicos. Solos e Rochas, v.27, n.2, p. 161-179, 2004.

FARNEZI, M. K. ; LEITE, A. L. L. Lateritic soil and bentonite mixtures assessment for liner usage purpose. Solos e Rochas, São Paulo, v. 30, n 2, p. 103-112, 2007.

HANNANT, L. Polymers and polymers composities. Construction materials: their nature and behavior, 2ed., London: J.M. Illston/E \& FN Spon, p. 359- 403, 1994.

HEINECK, K. S. Estudo do comportamento hidráulico e mecânico de materiais geotécnicos para barreiras horizontais impermeáveis. Tese (Doutorado) - Universidade Federal do Rio Grande do Sul, Porto Alegre, 2002. 234 p.

$\mathrm{KOCH}$, D. Bentonites as a basic material for technical base liners and site encapsulation cutoff walls. Applied Clay Science, v. 21, p. 1-11, 2002.

MICHALOWSKI, R.L.; CERMÁK, J. Triaxial compression of sand reinforced with fibers. Journal of Geotechnical and Geoenvironmental Engineering, v.129, n.2, p.125-136, 2003.

MORANDINI, T. L. C. ; LEITE, A. L. Characterization and hydraulic conductivity of some tropical soils samples and bentonite mixtures for CCL purposes. Engineering Geology, v.196, p. 251-267, 2015.

OSINUBI, K. J. ; NWAIWU, C. M. O. Compacted lateritic soils as hydraulic barriers in waste containment systems. In: INTERNATIONAL CONGRESS ON ENVIRONMENTAL

GEOTECHNICS, 4, Rio de Janeiro. Anais... p. 225-230, 2002.

SRIDHARAN, A.; NAGARAJ, H. B. Compressibility behaviour of remoulded, fine-grained soils and correlation with index properties. Canadian Geotechnical Journal, v. 37, p. 712722, 2000.

SIVAPULLAIAH, P. V.; SRIDHARAN, A.; Stalin, V. K. Evaluation of bentonite and sand mixtures as liners. In: INTERNATIONAL CONGRESS ON ENVIRONMENTAL GEOTECHNICS, 3, Lisboa. Anais... p. 17-21, 1998.

STEWART, D. I.; STUDDS, P. G.; Cousens, T. W. The factors controlling the engineering properties of bentonite-enhanced sand. Applied Clay Science, v. 23, p. 97-110, 2003.

TAYLOR, G.D. Materials in construction. 2ed. London: Longman Scientific \& Technical, 1994. 284p.

TERZAGHI, K.; PECK, R. B. Soil mechanics in engineering practice. 2nd edition, New York:Wiley, 1967. 